\title{
Review of the Clinical Approaches to the Use of Urine-based Tumor Markers in Bladder Cancer
}

\author{
Timothy Clinton, M.D. and Yair Lotan, M.D.* \\ Department of Urology, UT Southwestern Medical Center, Dallas, Texas, USA
}

\begin{abstract}
Bladder cancer is a common disease with a stable incidence for the past few decades despite advancements in molecular and genetic determinants of cancer development and progression. Cystoscopy remains the standard for detection and surveillance of bladder cancer, but it is an invasive and potentially costly procedure. With the knowledge of molecular alterations associated with bladder cancer numerous urinebased tumor markers have become commercially available. These urine markers have been evaluated in all clinical scenarios for the detection of bladder cancer including screening, hematuria, atypical cytology evaluation, and surveillance, but given the relative lack of impactful trials they are not routinely utilized. The efforts to develop markers with increased sensitivity to replace cystoscopy for the detection of bladder cancer have thus far been unsuccessful as well. This review addresses role of urine markers for screening, detection, and surveillance of bladder cancer.
\end{abstract}

KEY WORDS: Bladder cancer, screening, surveillance, urine tumor markers

\begin{abstract}
Abbreviations: AMH, asymptomatic microscopic hematuria; AUA, American Urological Association; BCG, Bacillus Calmette-Guérin; CIS, carcinoma in situ; FDA, US Food and Drug Administration; FISH, fluorescence in-situ hybridization; MIBC, muscle-invasive bladder cancer; NMIBC, non-muscle invasive bladder cancer; NPV, negative predictive value; PPV, positive predictive value; SEER, Surveillance, Epidemiology and End Results (database); TURBT, transurethral resection of bladder tumor.

Citation: Clinton T, Lotan Y. Review of the Clinical Approaches to the Use of Urine-based Tumor Markers in Bladder Cancer. Rambam Maimonides Med J 2017;8 (4):eo040. Review. doi:10.5041/RMMJ.10314

Copyright: (C) 2017 Clinton and Lotan. This is an open-access article. All its content, except where otherwise noted, is distributed under the terms of the Creative Commons Attribution License (http://creativecommons.org/licenses/by/3.0), which permits unrestricted use, distribution, and reproduction in any medium, provided the original work is properly cited.
\end{abstract}

Conflict of interest: Dr Lotan discloses research with Abbott, Pacific Edge, Mdxhealth, Genomedx, Cepheid, Photocure; and consulting for Mdxhealth, Photocure.

* To whom correspondence should be addressed. E-mail: Yair.lotan@utsouthwestern.edu 


\section{INTRODUCTION}

Bladder cancer remains the fifth most frequent noncutaneous malignancy in the United States with over 79,000 estimated new cases for $2017 .{ }^{1}$ The incidence of bladder cancer has remained stable from 1988 to 2006, and similarly the distribution of bladder cancer by stage has remained stable from 2004 to 2010 based on evaluation of the Surveillance, Epidemiology and End Results (SEER) database. .2,3 Despite advancements in biologic processes, genetics, diagnosis, treatment, and surveillance of bladder cancer the role of markers in identifying disease is still unclear. Urothelial carcinoma is by far the most common histologic subtype. The risk factors for urothelial carcinoma have been well established, with the most common being cigarette smoking. ${ }^{4}$ Approximately $75 \%$ of newly diagnosed bladder cancer cases present as non-muscle invasive bladder cancer (NMIBC). 5 With these non-invasive tumors the main treatment is bladder-sparing surgery with transurethral resection of tumor as well as a riskbased stratification of use of intravesical chemotherapy or immunotherapy to decrease risk of recurrence and/or progression. ${ }^{6,7}$ Unfortunately, despite attempts at initial control of NMIBC, $50 \%-70 \%$ recur, with $10 \%-20 \%$ progressing to muscleinvasive bladder cancer (MIBC). 5 Given the high relapse rates of NMIBC and the possibility of progression, frequent patient monitoring and surveillance is required.

The advances in understanding bladder cancer at the molecular and genetic level have led to the identification of detectable and measurable alterations associated with the disease. Given the ease of obtaining voided urine and its direct contact with potentially malignant urothelium, numerous urinebased tumor marker tests have been generated.
While white-light cystoscopy remains the standard for detection of bladder cancer, it is recognized that enhanced cystoscopy with blue light or narrow-band imaging frequently detects tumors that are missed by white light. ${ }^{8,9}$ In fact the American Urological Association (AUA) guidelines for managing NMIBC state that "in a patient with NMIBC, a clinician should offer blue light cystoscopy at the time of TURBT [transurethral resection of bladder tumor], if available, to increase detection and decrease recurrence (Moderate Recommendation; Grade B)." 7

While enhanced cystoscopy is currently available in the operating room, it is still not readily accessible in clinic for office cystoscopy. Hence urine markers have been investigated to replace or augment the accuracy of cystoscopy in the office setting primarily. At the time of writing, seven tests are comercially available: six are approved by the US Food and Drug Administration (FDA), and one meets Clinical Laboratory Improvement Act standards (Table 1). ${ }^{10}$ Currently NMP22, NMP22 BladderChek, and UroVysion all have FDA approval for detection of bladder cancer and in surveillance, while uCyt+, BTA TRAK, and BTA STAT only have approval for surveillance. ${ }^{10}$ This review will approach each step of current clinical approaches from diagnosis to surveillance of bladder cancer and what role urine markers can play in medical decision-making.

\section{DEVELOPMENT OF A CLINICALLY USEFUL MARKER}

A number of tests are available for screening, diagnosis, and staging of bladder cancer. The requirement for a biomarker to be valuable is that it needs to provide a benefit or improvement over the current standard evaluation. As has previously been described, an ideal biomarker needs to be "easier,

Table 1. Commercially Available Urine-based Tumor Markers.

\begin{tabular}{llll}
\hline Marker Type & \multicolumn{1}{c|}{ Test } & \multicolumn{1}{c|}{ Manufacturer } \\
\hline Protein-based & NMP22 & Alere, Waltham, MA, USA \\
& NMP22 BladderChek & \\
& BTA TRAK & Polymedco, Cortlandt Manor, NY, USA \\
& BTA STAT & \\
Cytologic immunohistochemistry & uCyt+ (Immunocyt) & Scimedx Inc., Denville, NJ, USA \\
\cline { 2 - 3 } Genetic-based & UroVysion FISH & Abbott Inc., Abbott Park, IL, USA \\
& Cxbladder & Pacific Edge Inc., Dunedin, New Zealand \\
\hline
\end{tabular}


better, faster, cheaper" than current standards. ${ }^{11}$ Point-of-care tests like NMP22 BladderChek and BTA STAT can provide information during an office visit that may allow more timely decision-making. However, the more sophisticated markers often require more time to perform. Cost is also an issue for markers that rely on more technical expertise.

While a majority of studies have focused on the detection and development of markers, there is a lack of quality assessment in prospective clinical trials. This review will focus on the following clinical scenarios:

- Screening

- Hematuria evaluation

- Atypical cytology or cystoscopic findings

- Surveillance of bladder cancer

\section{SCREENING POPULATION}

Bladder cancer mortality has remained relatively stable over the last few decades despite improvements in surveillance and treatment. ${ }^{12}$ Cancer screening has been shown to cause a major reduction in cancer mortality in breast, cervical, and colon cancer. ${ }^{13}$ Bladder cancer is a favorable candidate for screening, given the ease of collection of urine and its direct contact with potentially malignant urothelium, but at this time the US Preventive Services Task Force has deemed that there is insufficient evidence to support screening for bladder cancer. ${ }^{14}$ Unfortunately, early detection is vital in bladder cancer, given the stage-dependent survival rates and the fact that $25 \%$ of patients present with invasive or metastatic disease. ${ }^{12}$ Therefore, if screening can identify high-grade bladder cancer at an earlier asymptomatic stage this could translate to improved survival. Identifying a population with sufficient incidence is critical. ${ }^{15,16}$

\section{Prior Screening Studies}

Initial screening methods began with simple hemoglobin urine dipstick testing at home. Messing et al. prospectively screened 1575 men with 14 days of hemoglobin dipstick testing and found 258 (16\%) with positive chemical dipstick results for hematuria, with 21 (1.3\%) diagnosed with bladder cancer. ${ }^{17,18}$ The long-term follow-up study found that $4.8 \%$ of screen-detected tumors were muscleinvasive compared to $23.6 \%$ of a non-screened population, thereby demonstrating downstaging of bladder cancer due to screening. ${ }^{18}$ In the 14 years of follow-up, bladder cancer deaths were seen in $20 \%$ of unscreened patients but in none in the screened population. The weakness of this study was the lack of a randomized control arm. Other studies evaluating urine dipstick have had some conflicting results. A study by Britton et al. screened 2356 men with urine dipstick; 474 (20\%) had hematuria, of whom 319 underwent evaluation. ${ }^{19}$ This diagnosed only 17 asymptomatic NMIBC, but long-term follow-up demonstrated 5 patients who progressed and 3 who died of the disease. This study has many weaknesses, including likely understaging at the time of diagnosis.

While the use of hemoglobin dipstick is a cheap and manageable option for widespread screening, there are multiple urine-based tests that have superior sensitivities. Hence secondary screening with a urine marker may reduce number of cystoscopies needed. Roobol et al. evaluated a Dutch population with urine dipstick, and those subjects with microscopic hematuria underwent further urine molecular tests with NMP22, FGFR3, microsatellite, and methylation analysis; those who were positive underwent cystoscopic evaluation. ${ }^{20,21}$ Of the 1747 men who completed the protocol 409 (23.4\%) had hematuria, of whom 75 had at least one positive urine marker test, with only 4 non-invasive bladder tumors and 1 kidney cancer identified.

Given the limitations of prior studies due to the low prevalence of bladder cancer in screened populations, investigators began evaluating the utility of screening in high-risk populations. The risk factors associated with bladder cancer have been well delineated, and this led most investigators to focus on those with a smoking history or an occupational carcinogen exposure. ${ }^{16,22}$ Steiner et al. screened 183 patients with a greater than 40 pack-year smoking history with urine dipstick, NMP22, cytology, and UroVysion and identified 75 patients with at least one positive test. ${ }^{22}$ These patients underwent cystoscopic evaluation, and 3 were found to have NMIBC and 12 had either dysplasia or inverted papilloma. A larger study from Lotan et al. also screened a highrisk population with age over 50 and greater than 10-year smoking history or a significant high-risk occupation such as working with dyes, petroleum, or the chemical industry. ${ }^{16}$ In total 1502 patients were screened with NMP22 BladderChek test, 85 (5.7\%) having a positive test. Of these, 69 underwent cystoscopic evaluation, with identification of 2 NMIBC (one high-grade and one low-grade) and 1 patient with marked atypia. 


\section{Potential Role of Markers for Screening}

The National Cancer Institute lists two requirements that must be met for screening protocols to be efficacious: (1) the disease can be detected earlier than if the disease symptoms appear, and (2) there is evidence that treatment initiated earlier due to screening can result in an improved outcome. ${ }^{23-25}$ Identifying a high-risk population will be necessary for screening to be justified. Multiple studies have created individualized risk scores and predictive models that may predict the subgroups that are most at risk. ${ }^{26,27}$ One study has utilized a costeffectiveness model to identify a screening population and concluded that the ideal population would be one that has an incidence of bladder cancer of greater than $1.6 \% .{ }^{23}$

\section{HEMATURIA EVALUATION}

Hematuria (gross or microscopic) is the main symptom that leads to bladder cancer diagnosis, with an incidence of about $10 \%$ in those with gross hematuria and $2 \%-5 \%$ in those with microscopic hematuria. ${ }^{28}$ The American Urological Association (AUA) in 2012 developed guidelines for asymptomatic microscopic hematuria (AMH), defined as 3 red blood cells or greater per high-power field, and recommend cystoscopy for all adults over 35 with microscopic hematuria. ${ }^{29}$ Unfortunately AMH is also seen in $9 \%-18 \%$ of normal individuals; thus practitioners are faced with the decision of who should undergo this complete evaluation. Studies have now shown that a majority of patients with AMH fail to get referred to a urologist for cystoscopic evaluation. ${ }^{30,31}$ Delayed referral can result in a more advanced stage and hence a worse prognosis. ${ }^{2}$ Therefore, improving evaluation of patients with gross and microscopic hematuria may lead to more timely referral and earlier detection of the disease. Urine markers as well as clinical factors may play a critical role in risk-stratifying patients and possibly reducing the need to perform cystoscopy on very low-risk patients.

\section{Current Standard Hematuria Evaluation}

Hematuria evaluation currently utilizes cystoscopy for direct endoscopic evaluation of the bladder and imaging for evaluation of upper tract or renal abnormalities. ${ }^{29}$ The use of cystoscopy is the standard in bladder cancer diagnosis, with a high sensitivity, but false negative rates are variable and can be over 10\%. ${ }^{29,33}$ Therefore, practitioners will often utilize cytology as an adjunct test to aid in the detection of bladder cancer. Cytology is not recommended for every case by the AUA AMH guidelines but rather is only suggested as an option in those with persistent AMH after a negative evaluation or in those with risk factors for carcinoma in situ (CIS), such as irritative voiding symptoms, tobacco use, and chemical exposures. ${ }^{29}$ Cytology remains the adjunct test of choice due to its overall high specificity of $95 \%-$ 99\%.34 There are many limitations to the use of cytology, including its low sensitivity especially for low-grade cancer, interobserver variability, and atypical findings. Even though urine marker tests provide valuable information and almost all have a higher sensitivity than cytology for low-grade cancer, they are not routinely used due to the high rate of false positives leading to unnecessary and costly diagnostic procedures and increased patient anxiety. 34

\section{Potential Role of Markers in Hematuria Evaluation}

Given the low referral rates to urologists for hematuria evaluation, markers can potentially identify or stratify which patients truly need an evaluation. Lotan et al. developed a bladder cancer nomogram utilizing age, gender, smoking status, ethnicity, hematuria, and NMP22 BladderChek to define those most at risk of bladder cancer at time of cystoscopy. 35 The initial evaluation of the nomogram of 1272 patients had a predictive accuracy of 0.82 . This model was then validated in a prospective multicenter study for those patients referred for hematuria evaluation. ${ }^{36}$ Of 381 patients, 23 (6\%) were found to have bladder cancer, and the predictive accuracy remained similar at 0.79 . The main role of risk stratification would be to triage high-risk patients earlier and avoid cystoscopy in low-risk patients, such as women who do not smoke and have a negative marker. The safety of such approaches need validation.

The NMP22 BladderChek test evaluates a single protein in the urine, but there are recently developed panels of markers which may have improved sensitivity (Table 2). One such test is a new RNA assay, Cxbladder Detect, which has yet to be approved by the FDA but meets Clinical Improvement Act standards. In a prospective trial of 485 patients presenting with gross hematuria the bladder cancer incidence was 66 (13.6\%), and the test performed with a sensitivity of $81.8 \%$ and specificity of $85.1 \% .40$ Further stratification with removal of low-grade tumors increased the sensitivity and specificity to $91 \%$ and $90 \%$, respectively. Using the same RNA assay, Cxbladder Triage is a model that combines phenotypic factors (age, 
Table 2. Performance of Markers in Surveillance Setting from Pooled Analyses (Adapted from Chou et al. ${ }^{37}$ ).

\begin{tabular}{|lcc|}
\hline Test/Marker & Sensitivity $(95 \% \mathrm{Cl})$ & Specificity $(95 \% \mathrm{Cl})$ \\
\hline Cytology $^{38}$ & $0.35(0.13-0.75)$ & $0.94(0.85-1.00)$ \\
NMP22 & $0.61(0.49-0.71)$ & $0.84(0.75-0.90)$ \\
NMP22 BladderChek & $0.70(0.40-0.89)$ & $0.83(0.75-0.89)$ \\
BTA TRAK & $0.58(0.46-0.69)$ & $0.79(0.72-0.85)$ \\
BTA STAT & $0.60(0.55-0.65)$ & $0.76(0.69-0.83)$ \\
UCyt+ & $0.75(0.64-0.83)$ & $0.76(0.70-0.81)$ \\
UroVysion FISH & $0.55(0.36-0.72)$ & $0.80(0.66-0.89)$ \\
Cxbladder Monitor ${ }^{39}$ & 0.93 & NA \\
\hline Cl, confidence interval. & &
\end{tabular}

gender, frequency of macrohematuria, and smoking history) with genotypic variables in a voided urine sample. ${ }^{41}$ This model helps to triage patients presenting with hematuria from having to undergo a complete evaluation. The findings in the small discovery study of gross hematuria found a sensitivity of $95 \%$ and negative predictive value of $97 \%$. Further analysis of physician clinical decisions demonstrated that the Cxbladder test improves the management of asymptomatic hematuria by reducing the number of invasive procedures. ${ }^{42}$ If validated, Cxbladder Detect and Triage may replace cytology not only as an adjunct test but may possibly replace cystoscopy in certain settings.

\section{ATYPICAL CYTOLOGY}

\section{Potential Role of Markers in Evaluation of Atypical Cytology}

One of the main limitations of cytology is its often inconclusive findings with atypia. This cytology report creates a dilemma for urologists and patients in the setting of a negative cystoscopy, suspicious cystoscopy, or a patient with history of bladder cancer. Beyond the anxiety for patients, urologists must determine whether to observe the patient, with the risk of missed cancer resulting in progression, or biopsy every patient with atypia, placing the patient at risk of anesthesia and the procedure itself. To complicate the dilemma further, atypical cytology when biopsied can demonstrate malignancy in up to $23 \%$ of samples. 43 Given the increased sensitivity of many urine markers such as fluorescence in situ hybridization (FISH) and uCyt+ and the high speci- ficity of cytology, studies have shown that the combined analysis of these two tests reaches a high sensitivity and specificity. ${ }^{44-46}$ This has led to the evaluation of second-test reflex UroVysion and uCty+ testing in those with atypical or negative cytology.47-51 A prospective evaluation and subsequent validation study was performed by Lotan et al. and found a high sensitivity of the FISH assay to detect bladder cancer in patients with atypical cytology and an equivocal or negative cystoscopy.49,50 UroVysion had a high negative predictive value (NPV) and reasonable positive predictive value (PPV), such that patients with a negative UroVysion could avoid further evaluation and those with positive testing could be monitored more carefully or biopsied. Given these studies, urine marker testing for equivocal cytology has been included in the AUA NMIBC guidelines for those previously diagnosed with bladder cancer.7

\section{SURVEILLANCE OF BLADDER CANCER}

Surveillance of patients with bladder cancer has been the main focus for the use of diagnostic markers. In surveillance settings a test with maximal sensitivity is of utmost importance, and most of the new urinary marker tests have increased overall sensitivity as compared to cytology, but this is mostly driven by low-grade disease (Table 2). ${ }^{10}$ The predictive values of tests are also greatly improved due to a higher prevalence of the disease in surveillance as compared to screening populations. The AUA NMIBC guidelines currently do not recommend the use of urinary biomarkers in place of cystoscopic evaluation.7 


\section{Low-risk NMIBC Surveillance}

In low-risk NMIBC, the risk of progression is low, thus delays in identifying a recurrence is unlikely to be clinically significant. Therefore, the surveillance approach of low-risk NMIBC is to limit invasive procedures. Biomarkers can be utilized in this approach to aid in the reduction of cystoscopy frequency or define situations where a cystoscopy can be safely omitted.

The sensitivity of cytology is low for low-risk bladder cancer; therefore, surveillance relies almost solely on cystoscopy. All currently approved biomarkers including cytology have lower sensitivities for recurrent disease since tumor volumes tend to be smaller. ${ }^{8}$ Studies have combined biomarkers in a panel, and while the sensitivity for even low-risk bladder cancer was increased to as high as $93 \%$ the specificity was dismally low. $5^{2}$ Individual markers have been examined to determine whether they can replace cystoscopy, but none achieve a sensitivity sufficient to replace it.53,54

The use of biomarkers in low-risk bladder cancer will have to prove to be cost-effective, especially in a disease with minimal risk of progression such that some even consider watchful waiting. ${ }^{55,56}$ The use of biomarkers should therefore provide a surveillance protocol that can reduce the frequency of cystoscopy. An example of a modified surveillance approach has been demonstrated to be cost-effective while also decreasing the frequency of cystoscopy. ${ }^{57}$ The study investigated the sensitivity and cost of a range of urine markers and cystoscopy, and identified a cost-effective regimen of urine marker tests and cystoscopy alternating every 3 months. The model of cost-effective modified surveillance protocols requires prospective evaluation in a randomized trial to assess not only progression-free and overall survival but the financial outcomes as well.

\section{Intermediate-risk NMIBC Surveillance}

The intermediate-risk bladder cancer classification has historically been a catch-all for tumors that did not satisfy either low-risk or high-risk. $5^{8}$ Recently further identification of risk factors, such as multiple low-grade tumors, low-grade tumor size $\geq 3 \mathrm{~cm}$, early recurrence $<1$ year, or frequent recurrences, has provided evidence that some low-grade tumors harbor a more aggressive biology than previously thought.59 Therefore modified surveillance and treatment protocols for intravesical therapy have been developed specifically for this intermediaterisk group.7,58,60 Incorporating markers may allow more stringent monitoring without increasing cystoscopy procedures by alternating markers and cystoscopy. For example, a test such as Cxbladder Monitor which is designed to maximize sensitivity may be able to serve as a rule-out test so only patients with a positive test will undergo cystoscopy. 39 Other benefits were seen in a study that found that urologists who knew a patient had a positive test prior to cystoscopy were more likely to find a cancer. ${ }^{61}$ These different uses of biomarkers for augmented cystoscopic detection are ideal for these low-risk and intermediate-risk tumors as more urologists are able readily to treat these recurrent tumors with office-based fulguration, thereby limiting any delay to treatment or anesthetic risks.

\section{High-risk NMIBC Surveillance}

High-risk NMIBC is of great concern in surveillance due to its high risk of recurrence and progression. The sensitivity of markers alone is not sufficiently high to replace cystoscopy, but they have shown that adjunct use is beneficial. The NMP22 BladderChek test has been shown to increase the sensitivity of cystoscopy from $91.3 \%$ to $99.0 \%$ in those undergoing surveillance, for example. ${ }^{62}$ Recent evaluation of Cxbladder Monitor in those patients undergoing surveillance for NMIBC has demonstrated superiority with sensitivity of $91 \%$ and NPV of $96 \%$ as compared to current urine markers including cytology 63 There is still a need for studies that demonstrate cost-effectiveness and improved clinical management of high-grade cancer.

When developing a marker, it is important to identify the clinical significance of a positive result. For example, there are very few false positive results with cytology, and therefore the clinical management can rely on these findings. Unfortunately, there is insufficient evidence to determine what to do with a positive marker in the setting of a normal cystoscopy. Since specificity of common markers is no better than $75 \%$, many positive results can either be false or anticipatory. An anticipatory result means that the test is detecting microscopic disease, which may recur earlier but is not currently detectable. There is no clear intervention that can be used in this setting, and most of high-risk patients are already on maintenance Bacillus Calmette-Guérin therapy (BCG).

For example, patients with a positive UroVysion FISH test have a shorter time to recurrence than those whose test was negative, but the average time to recurrence was 12 months so it is not clear how 
management should change.48,64 It is still unclear how to incorporate markers in surveillance of highrisk disease, but a highly sensitive and specific marker could replace cytology.

\section{Assess Response to BCG}

Intravesical immunotherapy treatment with BCG is the standard of care in patients with high-risk bladder cancer and in some with intermediate risk.7,58 While BCG has been shown to decrease tumor recurrence and progression, there have been no studies to identify which tumors will fail treatment, i.e. those that are BCG-refractory. UroVysion is a potential test for monitoring failure of intravesical BCG treatment. ${ }^{65}$ In fact a recent prospective trial showed that UroVysion could predict response to BCG. ${ }^{66}$ Given the utility of this test, the AUA guidelines have included the use of UroVysion to assess response to BCG.7 This use of biomarkers to identify those that may benefit from certain treatments is the first step to developing individualized treatment for patients. These findings still need validation.

\section{FUTURE DEVELOPMENTS}

Use of urine markers has been limited due to a lack of efficient validation and effective integration into clinical decision-making. Given the vast number of studies and trials of the different markers, the differing study designs, patient selection, tumor prevalence, distribution of tumor grade and stage, different cutoff test values, and trial endpoints have made comparative analysis nearly impossible. ${ }^{67}$ There have been many studies and consortiums that have attempted to standardize the evaluation of molecular markers. ${ }^{68}$ The recent advancements of genetic information has led to the identification of new candidate molecular biomarkers. The preliminary results of some of these new biomarkers are promising, but there remains much more evaluation to identify the ideal marker that is "easier, better, faster, cheaper." ${ }_{11}$ Validating the results of biomarkers remains a challenge since it is necessary to perform prospective clinical trials to demonstrate added clinical value and, in today's financial environment, improved cost-effectiveness. ${ }^{67}$

\section{CONCLUSION}

There are many potential roles for urine markers in improving the detection and monitoring of bladder cancer. Growing understanding of cancer biology is enhancing our ability to identify potential urine markers. Identification of markers is just the first step in development since validation of clinical utility is often a neglected but critical step in establishing the value of urine markers in bladder cancer care.

\section{REFERENCES}

1. Siegel RL, Miller KD, Jemal A. Cancer statistics 2017. CA Cancer J Clin 2017;67:7-30. Crossref

2. Nielsen ME, Smith AB, Meyer A, et al. Trends in stage-specific incidence rates for urothelial carcinoma of the bladder in the United States: 1988 to 2006. Cancer 2014;120:86-95. $\underline{\text { Crossref }}$

3. Charlton ME, Adamo M, Sun L, Deorah S. Bladder cancer collaborative stage variables and their data quality, usage, and clinical implications: a review of SEER data, 2004-2010. Cancer 2014;120(23 suppl):3815-25. $\underline{\text { Crossref }}$

4. Rink M, Xylinas E, Babjuk M, et al. Impact of smoking on outcomes of patients with a history of recurrent nonmuscle invasive bladder cancer. J Urol 2012; 188:2120-7. $\underline{\text { Crossref }}$

5. Kaufman DS, Shipley WU, Feldman AS. Bladder cancer. Lancet 2009;374:239-49. $\underline{\text { Crossref }}$

6. Clark PE, Spiess PE, Agarwal N. NCCN Guidelines insights: Bladder cancer, Version 2.2016. J Natl Compr Canc Netw 2016;14:1213-24. $\underline{\text { Crossref }}$

7. Chang SS, Boorjian SA, Chou R, et al. Diagnosis and treatments of non-muscle invasive bladder cancer: AUA/SUO guideline. J Urol 2016;196:1021-9. $\underline{\text { Crossref }}$

8. Chou R, Selph S, Buckley DI, et al. Comparative effectiveness of fluorescent versus white light cystoscopy for initial diagnosis or surveillance of bladder cancer on clinical outcomes: systematic review and metaanalysis. J Urol 2017;197;548-58. Crossref

9. Kang W, Cui Z, Chen Q, Zhang D, Zhang H, Jin X. Narrow band imaging-assisted transurethral resection reduces the recurrence risk of non-muscle invasive bladder cancer: a systematic review and meta-analysis. Oncotarget 2017;8:23880-90.

10. Mbeutcha A, Lucca I, Matheu R, Lotan Y, Shariat SF. Current status of urinary biomarkers for detection and surveillance of bladder cancer. Urol Clin N Am 2016;43:47-62. $\underline{\text { Crossref }}$

11. Bensalah K, Montorsi F, Shariat SF. Challenges of cancer biomarker profiling. Eur Urol 2007;52:16019. $\underline{\text { Crossref }}$

12. Abdollah F, Gandaglia G, Thuret R, et al. Incidence, survival and mortality rates of stage-specific bladder cancer in United States: a trend analysis. Cancer Epidemiology 2013;37:219-25. Crossref 
13. Smith RA, Andrews KS, Brooks D, et al. Cancer screening in the United States, 2017: A review of current American Cancer Society guidelines and current issues in cancer screening. CA Cancer J Clin 2017;67:100-21. $\underline{\text { Crossref }}$

14. Chou R, Dana T. Screening adults for bladder cancer: a review of the evidence for the U.S. Preventive Services Task Force. Ann Intern Med 2010;153:4618. Crossref

15. Krabbe LM, Svatek RS, Shariat SF, et al. Bladder cancer risk: use of the PLCO and NLST to identify a suitable screening cohort. Urol Oncol 2016;33:65.e1925. $\underline{\text { Crossref }}$

16. Lotan Y, Elias K, Svatek RS, et al. Bladder cancer screening in a high risk asymptomatic population using a point of care urine based protein tumor marker. J Urol 2009;182:52-7. $\underline{\text { Crossref }}$

17. Messing EM, Bram LL, Young TB, et al. Comparison of bladder cancer outcome in men undergoing hematuria home screening versus those with standard clinical presentations. Urology 1995;45:387-97. Crossref

18. Messing EM, Madeb R, Young T, et al. Long-term outcome of hematuria home screening for bladder cancer in men. Cancer 2006;107:2173-9. Crossref

19. Britton JP, Dowell AC, Whelan P, Harris CM. A community study of bladder cancer screening by the detection of occult urinary bleeding. J Urol 1992; 148:788-90. Crossref

20. Roobol MJ, Bangma CH, el Bouazzaoui S, FrankenRaab CG, Zwarthoff EC. Feasibility study of screening for bladder cancer with urinary molecular markers (the BLU-P project). Urol Oncol 2010;28:686-90. Crossref

21. Bangma CH, Loeb S, Busstra M, et al. Outcomes of a bladder cancer screening program using home hematuria testing and molecular markers. Eur Urol 2013; 64:41-7. Crossref

22. Steiner H, Bergmeister M, Verdorfer I, et al. Early results of bladder-cancer screening in a high-risk population of heavy smokers. BJU Int 2008;59: 1026-31. Crossref

23. Lotan Y, Svatek RS, Sagalowsky AI. Should we screen for bladder cancer in a high-risk population?. Cancer 2006;107:982-90. Crossref

24. Lotan Y, Svatek RS, Malats N. Screening for bladder cancer: a perspective. World J Urol 2008;26:13-18. $\underline{\text { Crossref }}$

25. PDQ Screening and Prevention Editorial Board. PDQ Cancer Screening Overview. Bethesda, MD: National Cancer Institute. Updated October 7, 2016. Available at: http://bit.ly/2uy6lWw (accessed April 20, 2017). [PMID: 26389235]

26. Vickers AJ, Bennette C, Kibel AS, et al. Who should be included in a clinical trial of screening for bladder cancer? Cancer 2013;119:143-9. $\underline{\text { Crossref }}$

27. Wu X, Lin J, Grossman HB, et al. Projecting individualized probabilities of developing bladder cancer in white individuals. J Clin Oncol 2007;25:4974-81. Crossref

28. Grossfeld GD, Litwin MS, Wolf JS, et al. Evaluation of asymptomatic microscopic hematuria in adults: the American Urological Association best practice policy - part I: definition, detection, prevalence, and etiology. Urology 2001;57:599-603. $\underline{\text { Crossref }}$

29. Davis R, Jones JS, Barocas DA, et al. Diagnosis, evaluation and follow-up of asymptomatic microhematuria (AMH) in adults: AUA Guideline. J Urol 2012; 188(6 Suppl):2473-81. $\underline{\text { Crossref }}$

30. Nieder AM, Lotan T, Nuss GR, et al. Are patients with hematuria appropriately referred to Urology? A multi-institutional questionnaire based survey. Urol Oncol 2010;28:500-3. Crossref

31. Elias K, Svatek RS, Gupta S, Ho R, Lotan Y. High-risk patients with hematuria are not evaluated according to guideline recommendations. Cancer 2010;116: 2954-9. $\underline{\text { Crossref }}$

32. Wallace DMA, Bryan RT, Dunn JA, Begum G, Bathers S. Delay and survival in bladder cancer. BJU Int 2002;89:868-78. $\underline{\text { Crossref }}$

33. Schneeweiss S, Kriegmair M, Stepp H. Is everything all right if nothing seems wrong? A simple method of assessing the diagnostic value of endoscopic procedures when a gold standard is absent. J Urol 1999;161: 1116-19. $\underline{\text { Crossref }}$

34. Lotan Y, Roehrborn CG. Sensitivity and specificity of commonly available bladder tumor markers versus cytology: results of a comprehensive literature review and meta-analyses. Urology 2003;61:109-18. Crossref

35. Lotan Y, Capitanio U, Shariat SF, Hutterer GC, Karakiewicz PI. Impact of clinical factors, including a point-of-care nuclear matrix protein-22 assay and cytology, on bladder cancer detection. BJU Int 2009; 103:1368-74. Crossref

36. Lotan Y, Svatek RS, Krabbe LM, Xylina E, Klatte T, Shariat SF. Prospective external validation of a bladder cancer detection model. J Urol 2014;192:1343-8. Crossref

37. Chou R, Gore JL, Buckley D, et al. Urinary biomarkers for diagnosis of bladder cancer: a systematic review and meta-analysis. Ann Intern Med 2015;163:922-31. $\underline{\text { Crossref }}$ 
38. Van Rhijn BW, van der Poel HG, van der Kwast TH. Urine markers for bladder cancer surveillance: a systematic review. Eur Urol 2005;47:736-48. Crossref

39. Kavalieris L, O'Sullivan P, Frampton C, et al. Performance characteristics of a multigene urine biomarker test for monitoring for recurrent urothelial carcinoma in a multicenter study. J Urol 2017;197: 1419-26. Crossref

40. O'Sullivan P, Sharples K, Dalphin M, et al. A multigene urine test for the detection and stratification of bladder cancer in patients presenting with hematuria. J Urol 2012;188:741-7. Crossref

41. Kavalieris L, O'Sullivan PJ, Suttie JM, et al. A segregation index combining phenotypic (clinical characteristics) and genotypic (gene expression) biomarkers from a urine sample to triage out patients presenting with hematuria who have a low probability of urethral carcinoma. BMC Urology 2015;15:1-12. Crossref

42. Darling D, Luxmanan C, O'Sullivan P, Lough T, Suttie J. Clinical utility of Cxbladder for the diagnosis of urothelial carcinoma. Adv Ther 2017;34:1087-96. Crossref

43. Deshpande V, McKee GT. Analysis of atypical urine cytology in a tertiary care center. Cancer 2005;105: 468-75. $\underline{\text { Crossref }}$

44. Veeramachaneni R, Nordberg ML, Shi R, Herrera GA, Turbat-Herrera EA. Evaluation of fluorescence in situ hybridization as an ancillary tool to urine cytology in diagnosing urothelial carcinoma. Diagn Cytopathol 2003;28:301-7. Crossref

45. Daniely M, Rona R, Kaplan T, et al. Combined analysis of morphology and fluorescence in situ hybridization significantly increases accuracy of bladder cancer detection in voided urine samples. Urology 2005;66: 1354-9. Crossref

46. Tetu B, Tiguert R, Harel F, Fradet Y. ImmunoCyt/ $\mathrm{uCyt}+$ improves the sensitivity of urine cytology in patients followed for urothelial carcinoma. Mod Pathol 2005;18:83-9. Crossref

47. Skacel M, Fahmy M, Brainard JA, et al. Multitarget fluorescence in situ hybridization assay detects transitional cell carcinoma in the majority of patients with bladder cancer and atypical or negative urine cytology. J Urol 2003;169:2101-6. $\underline{\text { Crossref }}$

48. Yoder BJ, Skacel M, Hedgepeth R, et al. Reflex UroVysion testing of bladder cancer surveillance patients with equivocal or negative urine cytology: a prospective study with focus on the natural history of anticipatory positive findings. Am J Clin Pathol 2007;127:295-301. $\underline{\text { Crossref }}$

49. Lotan Y, Bensalah K, Ruddell T, Shariat SF, Sagalowsky AI, Ashfaq R. Prospective evaluation of the clini- cal usefulness of reflex fluorescence in situ hybridization assay in patients with atypical cytology for the detection of urothelial carcinoma of the bladder. $\mathrm{J}$ Urol 2008;179:2164-9. $\underline{\text { Crossref }}$

50. Schlomer BJ, Ho R, Sagalowsky A, Ashfaq R, Lotan Y. Prospective validation of the clinical usefulness of reflex fluorescence in situ hybridization assay in patients with atypical cytology for the detection of urothelial carcinoma of the bladder. J Urol 2010;183: 62-7. Crossref

51. Odisho AY, Berry AB, Ahmad AE, Cooperberg MR, Carroll PR, Konety BR. Reflex ImmunoCyt testing for the diagnosis of bladder cancer in patients with atypical urine cytology. Eur Urol 2013;63:936-40. Crossref

52. Todenhofer T, Hennenlotter J, Aufderklamm S, et al. Individual risk assessment in bladder cancer patients based on a multi-marker panel. J Cancer Res Clin Oncol 2013;139:49-56. $\underline{\text { Crossref }}$

53. Lodde M, Mian C, Comploj E, et al. uCyt+ test: alternative to cystoscopy for less-invasive follow-up of patients with low risk of urothelial carcinoma. Urology 2006;67:950-4. $\underline{\text { Crossref }}$

54. Schmitz-Drager C, Bonberg N, Pesch B, et al. Replacing cystoscopy by urine markers in the followup of patients with low-risk non-muscle-invasive bladder cancer? - An International Bladder Cancer Network project. Urol Oncol 2016;34:452-9. Crossref

55. Pruthi RS, Baldwin N, Bhalani V, Wallen EM. Conservative management of low risk superficial bladder tumors. J Urol 2008;179:87-90. $\underline{\text { Crossref }}$

56. Klaassen Z, Soloway MS. European Association of Urology and American Urological Association/ Society of Urologic Oncology Guidelines on risk categories for non-muscle-invasive bladder cancer may lead to overtreatment for low-grade Ta bladder tumors. Urology 2017;105:14-17. Crossref

57. Lotan Y, Roehrborn CG. Cost-effectiveness of a modified care protocol substituting bladder tumor markers for cystoscopy for the followup of patients with transitional cell carcinoma of the bladder: a decision analytical approach. J Urol 2002;167:75-9. Crossref

58. Babjuk M, Bohle A, Burger M, et al. EAU Guidelines on non-muscle-invasive urothelial carcinoma of the bladder: Update 2016. Eur Urol 2017;71:447-61. Crossref

59. Kamat AM, Witjes JA, Brausi M, et al. Defining and treating the spectrum of intermediate risk nonmuscle invasive bladder cancer. J Urol 2014;192:305-15. Crossref

6o. Kassouf W, Traboulsi SL, Schmitz-Drager B, et al. Follow-up in non-muscle-invasive bladder cancer - 
International Bladder Cancer Network recommendations. Urol Oncol 2016;34:460-8. Crossref

61. Van der Aa MN, Steyerberg EW, Bangma C, van Rhijn BWG, Zwarthoff EC, van der Kwast TH. Cystoscopy revisited as the gold standard for detecting bladder cancer recurrence: diagnostic review bias in the randomized, prospective CEFUB Trial. J Urol 2010;183:76-80. Crossref

62. Grossman HB, Soloway M, Messing E, et al. Surveillance for recurrent bladder cancer using a point-ofcare proteomic assay. JAMA 2006;295:299-305. Crossref

63. Lotan Y, O'Sullivan P, Raman JD, et al. Clinical comparison of noninvasive urine tests for ruling out recurrent urothelial carcinoma. Urol Oncol 2017 Mar 30. [Epub ahead of print]. Crossref

64. Seideman C, Canter D, Kim P, et al. Multicenter evaluation of the role of UroVysion FISH assay in surveillance of patients with bladder cancer: does
FISH positivity anticipate recurrence? World J Urol 2015;33:1309-13. Crossref

65. Kipp BR, Karnes J, Brankley SM, et al. Monitoring intravesical therapy for superficial bladder cancer using fluorescence in situ hybridization. J Urol 2005; 173:401-4. Crossref

66. Kamat AM, Dickstein RJ, Messetti F, et al. Use of fluorescence in situ hybridization to predict patient response to BCG therapy for bladder cancer: results of a prospective trial. J Urol 2012;187:862-7. Crossref

67. Lotan Y, Shariat SF, Schmitz-Drager BJ, et al. Considerations on implementing diagnostic markers into clinical decision making in bladder cancer. Urol Oncol 2010;28:441-8. Crossref

68. Goebell PJ, Groshen SL, Schmitz-Drager BJ. Guidelines for development of diagnostic markers in bladder cancer. World J Urol 2008;26:5-11. Crossref 